\title{
AS FERRAMENTAS USADAS PARA A FORMAÇÃO NEOLÓGICA NA LÍNGUA ÁRABE: A TERMINOGRAFIA DAS LÍNGUAS DE ESPECIALIDADE COMO OBJETO DE ESTUDO
}

Elias Mendes Gomes'

Aвstract: The expansion of the Arabic language to beyond its historical borders followed the Islamic territorial conquest. The contact with the pockets of Hellenic culture, revealed a terminological vacuum in the lexicon of those Bedouins from the Arabian Peninsula, as there was no technical vocabulary to express the notions already consecrated in the languages of the conquered cultures. The same situation is repeated in the "recent" technological invasion from the western world which led to the uncontrollable formation of neologisms, and the subsequent creation of the Language Academies in the different Arab nations to regulate the incorporation of new terms to the lexicon.

The Arabic language reacted in different ways to the foreign concepts brought in by these new ideas and concepts. Their addition to the lexicon was done through the tools explored in this article: /ichtiqāq/ morphologic derivation, /majāz/ semantic broadening, /tacrīb/ borrowing (literally "arabization"), and /naht// compounding.

KeYwords: Arabic, Terminology, Neologism.

"Uma língua pura é uma língua pobre."

(Jamal Al-Qinai)

1 Mestrando do Programa de Pós-graduação em Língua, Literatura e Cultura Árabe. Universidade de São Paulo (DLO). Bolsista CAPES. 


\section{A língua árabe: 0 elemento em foco}

A linguagem - o principal veículo através do qual os seres humanos se comunicam - sempre encantou e mistificou a humanidade. Devido a isso, teo. rias, hipóteses e especulações sobre a sua origem e desenvolvimento remontam a milhares de anos. Longyear (2000) advoga que a primeira tentativa de sistematizar a linguagem deve-se aos filósofos gregos que especularam sobre sua origem e o relacionamento entre os diferentes objetos e seus nomes. Depois disso os filósofos começaram a discutir as regras que governam a linguagem, isto é, a gramática. E, finalmente, no século III a. C., eles começaram a codificar as palavras de acordo com as diferentes partes do discurso e a cunhar denominações para as diferentes formas de verbos e substantivos.

No universo linguístico árabe a preocupação pela sistematização começou no século VIII d. C. como resultado da expansão hegemônica árabe. Historicamente, a rica língua árabe - com a prosa e a poesia altamente desenvolvidas na época da Jāhilīya (a era pertencente ao período pré-islâmico) - sempre teve seu indiscutível lugar na Península Arábica, mas com o advento e expansão do islamismo ela ganhou a projeção que a levou para além de suas fronteiras linguísticas históricas.

Esposito (1999) e Versteegh (1997) atestam que o papel preponderante que a língua árabe desempenhava na recém-criada liturgia islâmica, bem como o domínio político da nação árabe nos territórios conquistados, requeria uma inadiável estruturação linguística. Respondendo a essa necessidade o filólogo Khalil Ibn-Ahmad (ca.718-791), procedente da província onde se encontra 0 moderno Sultanato de Oman, compilou o inteiro vocabulário árabe em uma única obra, o Kitāb al-Ayn (o livro [da letra] 'ayn). Khalil Ibn-Ahmad também fundou a primeira escola de filologia do mundo árabe, onde seus discípulos analisaram a língua e fixaram a gramática árabe. Com o passar do tempo, outtras escolas foram originadas (frequentemente antagonistas entre si), mas sel alvo era sempre o de preservar a língua árabe como revelada no Alcorão (0 sagrado livro islâmico).

A tradição dicionarística principiada por Khalil Ibn-Ahmad não parou na lexicografia de língua geral. Demai (2006, p. 64) afirma que "há indicaçốes de que a Terminologia no Oriente se iniciou já no século IX, sendo que os árabes 
foram seus principais representantes". No Ocidente, o mesmo estudo sistemático com preocupação normalizadora aconteceu apenas a partir do século XVI com a obra de Versalius, versando sobre a terminologia da anatomia. No século XVIII surgiram as obras de Lavoisier e Bertholet, sobre a terminologia da química. Kennedy-Day (2003) valida a postulação de Demai ao afirmar que o tratado de terminologia filosófica mais antigo de que se tem notícia foi o kitāb al-ḥudūd, a obra composta pelo gramaticista árabe Al-Farra' (morto em 822 d.C.); essa obra, contudo, não sobreviveu. Entretanto, a tradição terminológica com ênfase na criação, sistematização e normatização do vocabulário de especialidade, nesse caso, o filosófico, foi continuada com a obra Epístola sobre a definição das coisas e suas descrições, de Al-Kindī, o primeiro filósofo árabe. Nela, Al-Kindī inventariou, descreveu e ordenou uma lista de termos filosóficos provenientes do grego, dando a eles uma forma paralela na língua árabe.

Os árabes se depararam com este mesmo vácuo terminológico em sua língua em pelo menos três momentos históricos específicos: 1 . No período das grandes traduções, quando os árabes, na qualidade de herdeiros e detentores da civilização greco-romana, verteram as obras clássicas do saber grego para a língua árabe; 2. Durante a Renascença Árabe do século XIX, que foi precedida pela expedição militar de Napoleão ao Egito e o consequente envio de eruditos islâmicos à Europa a fim de estudarem as novas ideias; 3. A "recente" invasão tecnológica do mundo ocidental que desencadeou a formação de neologismos de maneira selvagem e a consequente formação das Academias de Língua nas diferentes nações árabes para regular a inserção de novos vocábulos ao léxico.

A língua árabe reagiu de maneira diferente aos "estrangeirismos" trazidos por essas novas ideias e conceitos. A inserção das noções já consagradas nas línguas de outras culturas em seu léxico foi feita através das ferramentas que serão estudadas neste artigo: /ichtiqāq/ derivação morfológica, /majāz/ ampliação semântica, $/ \operatorname{ta}^{c} \mathbf{r}^{\mathrm{r}} \mathrm{b} / \mathrm{empréstimo} \mathrm{(literalmente} \mathrm{"arabização")} \mathrm{e} \mathrm{/naht/}$ composição lexical.

\section{Línguas em contato: $\mathrm{O}$ árabe e as línguas da tecnologia moderna}

A cultura ocidental impactou o mundo de maneira sui generis no início do século XX. As modernas ciências e tecnologias floresceram e os árabes, agora 
divididos em Estados politicamente independentes, preocuparam-se com a modernização de suas sociedades. Países que até então tinham estado isolados dos centros de pesquisa científica viram-se unidos através da mídia moderna. A fim de abarcar o conhecimento, os árabes sentiram a necessidade de criar instituições científicas oficiais capazes de ajudar no processo de modernização, particularmente no âmbito do grande vácuo terminológico existente na língua árabe para exprimir as ideias ocidentais.

Alguns países, quando confrontados com o mesmo problema, arquitetaram uma revolução linguística, como é o caso da Turquia e da Malásia (e, mais recentemente, Israel). Entretanto, o mesmo não é possível para o mundo árabe, uma vez que não é possível impor uma norma nos 20 países que têm a língua árabe como língua nacional.

O estabelecimento das Acadẹmias Árabes (a partir de 1919) foi um passo concreto em direção a uma normalização da terminologia em nível transnacional. De acordo com El-Khafaifi (1985, p. 34-6), o principal propósito dessas academias é a "adaptação da língua às necessidades dos tempos modernos a fim de que ela possa funcionar com êxito".

A primeira academia a ser estabelecida foi a de Damasco (1919), seguida pela do Cairo (1932), a de Bagdá (1947) e a de Amman (1976). Em 1967 foi fundada em Rabat uma repartição internacional, o Departamento de Coordenação Permanente. Esse último difere das academias árabes por se preocupar com a estandardização do árabe moderno, em vez da criação de nova terminologia. Chejne (1969) afirma que todas as academias compartilham os mesmos objetivos de preservação e revitalização do árabe clássico como uma língua unificada para todos os falantes do árabe. Esse alvo é atingido através do patrocínio a pesquisas em linguística árabe, cunhagem de palavras (de acordo com os padrões morfológicos e fonológicos do árabe) que substituirão a estrangeirismos etc. El-Khafaifi (1985) complementa essa ideia ao atestar que as academias não estavam interessadas apenas na cunhagem de palavras derivadas de raízes árabes, ou na "arabização" de empréstimos estrangeiros, mas, também, em reviver palavras árabes arcaicas cujo sentido poderia ser aplicados às necessidades do mundo moderno.

A Academia do Cairo é uma das mais ativas em seu papel de fortalecer a língua árabe. Ela tem 25 comitês, e a maioria deles ocupa-se com a cunhagem 
de equivalentes árabes para os termos estrangeiros. At-Tarzi (1999), citado por Al-Qahtani (2000, p. 28), diz que a tarefa da Academia é a de "manter a pureza do árabe, fazendo-o capaz de expressar os novos avanços das ciências e artes, e desenvolver um novo dicionário para a língua”.

Os neologismos cunhados pela academia variam de acordo com os campos de conhecimento. "De acordo com o relatório estatístico apresentado na 64 conferência (1997), o número de termos cunhados pela Academia de Língua do Cairo até então era 135.076" (AL-QAHTANI, 2000, p. 30). A título de amostragem, apresenta-se aqui aqueles domínios científicos onde se nota a maior inserção de termos:

$\begin{array}{lc}\text { Domínio do Conhecimento } & \text { Número de Termos } \\ \text { Biblioteconomia e Ciências da Informação } & 1.732 \\ \text { Filosofia } & 4.903 \\ \text { Ciências Sociais } & 1.969 \\ \text { Economia } & 1.628 \\ \text { Direito } & 9.113 \\ \text { Cultura } & 1.002 \\ \text { Matemática } & 4.120 \\ \text { Física } & 14.746 \\ \text { Química } & 7.773 \\ \text { Geologia } & 9.486 \\ \text { Biologia } & 20.750 \\ \text { Medicina } & 20.031 \\ \text { Engenharia } & 5.492 \\ \text { Hidrologia } & 4.944 \\ \text { Petróleo } & 11.147 \\ \text { Artes } & 2.391 \\ \text { Música } & 1.584 \\ \text { Esportès } & 1.710 \\ \text { História } & 1.062 \\ \text { Geografia } & 3.437\end{array}$

Essa amostragem refere-se apenas à Academia Cairota, que é a mais estudada e a de maior influência no mundo árabe (EL-KHAFAIFI, 1985). Entretanto, 
é legítimo dizer que todas as academias têm se envolvido na tarefa de modernização do árabe. Um dos problemas encontrados é a quantidade de termos, bem como a velocidade com a qual as mudanças ocorrem nos campos da ciência e tecnologia. Um cientista dificilmente esperaria pelos termos cunhados pela academia antes de publicar sua pesquisa. Dessa maneira, uma enxurrada de termos provindos do próprio meio acadêmico infiltra a língua antes que as academias tenham tempo hábil para cunhar a terminologia apropriada.

De acordo com El-Mouloudi (1986) todas as academias têm seguido o método tradicional de inserção na língua, sancionado pelos linguistas e gramáticos do passado. Ele censura essa abordagem e culpa a academia pela demora na apresentação de nova terminologia: "um principio predominante que tem guiado [a academia] e ao mesmo tempo diminuído a produtividade lexical tem sido o apoio quase que total nos antigos métodos de nomeação para ideias e conceitos" (p. 98). De acordo com ele, essa insistência em seguir os métodos tradicionais de cunhagem é problemática porque muitos dos termos da moderna linguagem científica (muitas vezes derivados de línguas indo-europeias) foram, originalmente, aglutinados com prefixos e sufixos (gregos e latinos), e o árabe não tem, em sua estrutura, equivalentes para tais conceitos. Da mesma forma, o uso de composição sintagmática, comum na formação de conceitos científicos, não é muito frequente em árabe.

\section{Terminologia e terminografia árabe}

Uma das peculiaridades da língua árabe é a maneira pela qual os vocábulos são formados. Trata-se do sistema de derivação. Embora, na lingua árabe, nem todas as palavras possam ser associadas a uma raiz verbal, a maioria de seus lexemas deriva de um verbo simples. Essa combinação de grafemas traz em seu bojo uma noção específica. Assim, a composição /k-s-r/ representa a ideia de "quebrar", enquanto e /d-r-s/ exprime o conceito de "estudar", /q-w-l/ o de "falar", e assim por diante.

Prefixos, sufixos e mudanças internas (tanto em acréscimos como em supressões) inseridos nessa raiz dão origem a novos termos relacionados à ideia principal. Esse processo é conhecido em árabe como /ichtiqāq/, ou seja, deri- 
vação analógica (EL-KHAFAIFI, 1985; ARYAN, 2001; TARAZĪ, 2005), que é o método mais produtivo utilizado para a formação de neologismos em árabe. Toda raiz árabe tem em seu âmago o mesmo potencial para derivação e geração de novos vocábulos. Dessa maneira poder-se-ia dizer que a capacidade para expansão de vocabulário é virtualmente ilimitada.

Não obstante, faz-se necessário esclarecer que, para que esses novos vocábulos sejam reconhecidos e aceitos não somente por filólogos e linguistas, mas pelos próprios falantes nativos, eles têm que seguir paradigmas previamente estabelecidos na linguagem, ou seja, o /qiyās/ (métrica ou paradigma), que é o conceito linguístico que determina as formas válidas para a derivação, que normalmente são operantes na linguagem e não apenas imposições artificiai. ${ }^{2}$ Testificando da produtividade desse método, El-Khafaifi, declara:

Ao remeter-se a fontes já estabelecidas, isto é, às milhares de raízes árabes existentes, o processo de derivação pode gerar um vasto conjunto de novas palavras. Esse método de aumento da língua árabe tem estado em uso desde o começo da linguagem, e contribuiu grandemente para o seu enriquecimento lexical e para o seu crescimento e desenvolvimento através dos séculos. $(1985$, p. 68)

A título de ilustração tome-se por exemplo o radical /k-t-b/, que denota a ideia de escrever. Em sua forma mais simples o trigrama KaTaBa significa "ele escreveu". Por convenção, essa estrutura é usada como a forma essencial do verbo, que equivale ao infinitivo nas línguas do tronco indo-europeu.

Ao acrescentar-se um "m" ao trigrama maKTaB, obtém-se "escritório" ou "escrivaninha", ou seja, o local onde se escreve. KiTāB refere-se a um livro, enquanto maKTaBa representa a ideia de biblioteca, ou o lugar onde os escritos são armazenados. KāTiB é aquele que performa a ação de escrever, ou escritor, escriturário - enquanto maKTūB é a obra produzida, ou seja, o "escrito", “carta”.

2 Havendo dito isso, é importante ressaltar que há exceções a essa regra. O conceito conhecido por $\underline{\text { as-sama } \bar{a}^{c}}$ refere-se àqueles termos irregulares que não se conformam aos paradigmas estabelecidos, mas que, de uma maneira ou de outra, encontraram sua aceitação no léxico dos falantes árabes. Esses neologismos, porém, são considerados como anômalos. 
Em sua forma deverbal (mas dar - o primeiro substantivo derivado da forma verbal), KiTāBa, refere-se à escrita em si.

A maioria das raízes árabes tem padrões derivacionais semelhantes. Os princípios e regras da língua árabe foram delineados pelos antigos gramáticos árabes que formularam suas hipóteses da gramática árabe baseados essencialmente em noções matemáticas e, firmados em observação, comparação e generalização dos paradigmas, desenvolveram o conceito de /qiyās/ (molde, paradigma) da derivação. Por analogia, potencialmente, quase toda raiz verbal pode originar novas palavras se for seguida a estrutura descrita acima (EL-MOULOUDI, 1986).

Al-Qahtani (2000) ilustra esse processo com a comparação entre os dois vocábulos seguintes: /maKTaB/ "escritório, ou lugar onde se escreve"; /maQRa'/ "lugar onde se lê". Note-se que o vocábulo/maqra'/ não existe oficialmente em árabe, mas, se houvesse a necessidade, a denominação poderia ser criada. Esse é o método mais usado pelas academias de língua árabe: um molde serve de arcabouço ou paradigma para a formação de novos vocábulos.

Esse processo, /ichtiqāq/, pode ser usado para a obtenção de termos usados no domínio da ciência ou denominações para aparelhos que fazem parte da vida moderna:

\begin{tabular}{|c|c|c|}
\hline Termo árabe & Significado & Derivado do vocábulo \\
\hline /sammāca/ & fones de ouvido & /sammaca/ fazer alguém ouvir \\
\hline /thallāja/ & Refrigerador & / thalj/ gelo \\
\hline /ġassāla/ & máquina de lavar & /ġassala/ lavar \\
\hline / khallāta/ & Liquidificador & / khallata/ misturar \\
\hline /raqqās / & Pêndulo & /raqqașa/ dançar \\
\hline
\end{tabular}

Derivação parece ser um paradigma morfológico muito produtivo em árabe, e é frequentemente um processo 'espontâneo' compartilhado por todos os falantes nativos de árabe. As academias de língua preferem a derivação a qualquer outro método de arabização. Entretanto, em alguns casos, não há escolhas e outros méé todos, isto é, composição lexical, ampliação semântica e empréstimos têm que sêr usados. (AL-QAHTANI, 2000, p. 77) 
Uma segunda forma muito produtiva usada para a expansão lexical terminológica é o fenômeno conhecido como "empréstimo" ou / $\mathrm{ta}^{c} \mathrm{rīb} /$ (lit. arabização). A convenção de adotar termos estrangeiros para expressar conceitos novos é comum no domínio terminológico em todas as línguas, porque esses vocábulos não têm a "bagagem" que outros teriam. Eles são "artificiais", fato que lhes proporciona uma utilidade sui generis na tarefa de representar uma ideia. "Na medida em que empréstimos linguísticos estrangeiros são páginas brancas na linguagem receptora, eles exibem uma pureza [linguística] que palavras nativas não têm" (KENNEDY-DAY, 2003, p. 23).

Entretanto, esse método sempre causou inúmeros debates entre os eruditos e academicistas, que se julgam detentores da tarefa de salvaguardar o árabe de uma potencial ruptura em sua estrutura e integridade linguística. Muitos deles consideram que a língua árabe tem em sua estrutura a pontencialidade de gerar os termos científicos necessários sem recorrer a empréstimos de línguas estrangeiras. El-Khafaifi (1985) ilustra esse tipo de atitude com o exemplo de Ahmad Al-Iskandarī (eminente erudito, graduado na Universidade de AlAzhar e um dos membros fundadores da Academia do Cairo):

Ele [Al-Iskandarī] atribui a adoção de muitas palavras estrangeiras às traduções feitas durante os tempos medievais, especialmente durante o tempo do Califa Al-Ma'mūn por pessoas as quais ele acusa de serem "estrangeiros arabizados", e preguiçosos, cujo árabe era imperfeito; se eles soubessem o árabe, alega ele, eles teriam encontrado uma autêntica forma árabe para cada palavra que eles traduziram, em vez de simplesmente adotarem a palavra estrangeira e arabizá-la. (p. 162)

A preocupação de $\mathrm{Al}$-Iskandarī é justificável, embora extremada. Há indicações de que durante o período das grandes traduções muitos termos foram acoplados à língua sem muito escrutínio, mas isso certamente não ocorre (pelo menos não na mesma frequência) nos dias atuais.

Os primeiros tradutores das ciências gregas para o árabe certamente foram confrontados com o vácuo terminológico nos mais variados domínios da ciência. Khamloussy (1995) atesta que Hunayn Ibn Ishāạ (e sua escola) usou 
tanto o processo de $/ \mathrm{ta}^{\mathrm{c}} \mathrm{rīb} /$ quanto o de /ichtiqāq/, embora o primeiro tenha sido usado com maior frequência nas primeiras traduções. Mas, a área da ciência na qual Hunayn se especializou (tradução de tratados médicos e farmacológicos, especialmente os de Galeno) justifica sua postura "incorporadora" de termos, uma vez que a medicina exige essa acuidade quando se trata da identificação de enfermidades, seus sintomas e seus tratamentos. Cada planta e demais ingredientes utilizados no processo de cura deveriam ser identificados e descritos com exatidão. Além do mais, como já foi mencionado acima, / ta $^{\mathrm{c}}{ }^{\mathrm{r}} \mathrm{i} \mathrm{b} /$ foi a válida resposta a uma necessidade temporária confinada a um preciso momento na história árabe:

A primeira abordagem consiste em tomar uma palavra ou termo da línguafonte e transferi-la para a língua de chegada. O termo é naturalizado, isto é, transliterado em árabe. Essa abordagem era mais comum nas primeiras traduções. Uma vez que os tradutores tivessem se tornado familiarizados com o termo e o conceito que este representava, eles geralmente se sentiam livres para criar um equivalente árabe para o mesmo. (KHAMLOUSSY, 1995, pp. 31-2)

O árabe moderno, de certa forma, tem seguido de perto as recomendações que as academias espalhadas pelas diversas nações árabes têm sancionado. Somente se recorre a empréstimos linguísticos quando todas as outras tentativas de produzir uma forma genuinamente nativa falharam; nesse caso; os empréstimos precisam se harmonizar com que se harmonize com o sistema inerente da linguagem, a fim de que sua conspicuidade seja a menor possível (EL-KHAFAIFI, 1985).

Essa é a perspectiva teórica. Algumas vezes, entretanto, a academia pode sugerir um termo que não encontra receptividade por parte dos falantes da língua. Um exemplo disso é a sugestão para o termo "sanduíche": /ichchatar walmachtūr walkāmikh baynahumā/ "uma parte e a outra parte, e o 'molho' entre os dois". ${ }^{3}$ Esse é um exemplo clássico e até extremado, mas, particu-

3 Exemplo fornecido por Profa. Dra. Safa Jubran - DLO/USP. Ad tempora. 
larmente na linguagem da ciência, a prática tem sido um pouco diferente. $\mathrm{O}$ influxo de novos conceitos é tão numeroso e rápido que as academias não têm tido condições de prover resposta em tempo hábil, e os equivalentes em árabe se tornam cópias-carbono de seus correlativos na língua estrangeira: / kribtūkūkis/ "criptococo", /hīmūglūbīn/ "hemoglobina", /kalsiyūm/ "cálcio", / alūmīniyūm/ "alumínio".

Assim chega-se às duas acepções diferentes que o controversial conceito de / ta ${ }^{\mathrm{c}} \mathrm{rī}$ / tem no domínio linguístico: (a) tradução de termos de uma língua estrangeira para o árabe e (b) empréstimo de um termo estrangeiro que, quando possível, é adaptado às convenções fonológicas, morfológicas e ortográficas da convenção árabe (EL-KHAFAIFI, 1985; WEHR, 1979). Dessa maneira, as práticas de decalque e deslize linguísticos são englobadas sob o conceito de /tacrīib/.

O terceiro método para a formação de neologismos em árabe é o /majāz/, ou seja, a ampliação semântica. Isso se refere ao processo de agregar um novo sentido a um vocábulo já existente. Por exemplo, o conceito “átomo" é representado em árabe com o termo /darra/ que originalmente, se referia a de uma formiguinha. Assim, uma nova acepção foi acrescentada à palavra original.

Al-Qahtani (2000, p. 84) afirma que /majāz/ tem sido usado para denominar conceitos novos. "Academias linguísticas tentam se aproveitar de termos árabes arcaicos que foram esquecidos para expandir sua conotação semântica a fim de abarcar novos sentidos." Seguem-se alguns exemplos de como o / mājaz/ tem sido usado na neologia terminológica:

\begin{tabular}{|c|c|c|}
\hline Termo árabe & Significado atual & Ampliação semântica do vocábulo \\
\hline /qitāar/ & trem & sucessão de camelos (em fila indiana) \\
\hline /qātira/ & locomotiva & o camelo-guia (o camelo em comando) \\
\hline /waqūd/ & combustível & lenha \\
\hline /'itār/ & Pneu & moldura circular \\
\hline
\end{tabular}

O quarto, e o mais controvertido paradigma para criação de neologismos, é o /naḥt/, ou seja, a composição lexical. O termo é derivado do trigrama /n-h-t/, que significa "entalhar" ou "esculpir" em algum tipo de material sólido 
(WEHR, 1979), em linguística veio a significar o amálgama de parte (ou totalidade) de duas ou mais palavras dando origem a uma terceira. Em português exemplos seriam palavras como /motel/, derivada de "motorista" e "hotel", e os sintagmas compostos como /saia-calça/, /couve-flor/, /sapatênis/ etc.

Tradicionalmente, raros tradutores (e, por consequência, terminógrafos) lançaram mão dessa ferramenta, embora, nos primórdios da era islâmica, verbos tenham sido criados para descrever as várias fórmulas bem conhecidas (geralmente no âmbito litúrgico-religioso). El-Khafaifi (1985), ilustra esse caso com o exemplo de /basmala/ exprimindo a expressão formulaica / bismillāh al-rahmān al-rahīm/ (Em nome de Deus, o clemente, o misericordioso). O verbo é composto dos três primeiros morfemas na frase: bi (em), ism (nome) e Allah (Deus). Balāsi (1999, pp. 275-8) exemplifica:

\begin{tabular}{|l|l|}
\hline \multicolumn{1}{|c|}{ Termo árabe } & \multicolumn{1}{c|}{ Derivado das frases feitas } \\
\hline /ḥahcala/ & $\begin{array}{l}\text { /ḥaya cala așalā, haya cala alfalāḥ/ "venha para a oração, venha } \\
\text { para a salvação" }\end{array}$ \\
\hline /ḥawqala/ & $\begin{array}{l}\text { /lā ḥawl wala qwa illa billah/ "não há poderio ou força a não ser } \\
\text { em Deus" }\end{array}$ \\
\hline
\end{tabular}

A falta de precedentes históricos significantes que sancionem esse processo de criação de nova terminologia tem criado reservas e divergências quanto a sua utilização. Entretanto, a realidade e as pressões do mundo atual, com sua enxurrada de termos técnicos provindos das novas especializações, requerem que o naht seja usado com maior frequência, mesmo a contragosto dos academicistas (EL-KHAFAIFI, 1985).

O caráter derivacional do árabe desempenha um papel importante na criação de novo vocabulário, afinal, existem milhares de raízes das quais se poderia extrair novas combinações. Entretanto, isso não implica dizer que éo único método a ser utílizado. Abaixo estão alguns exemplos de como esse processo tem sido utilizado, particularmente no meio científico, onde o aspecto "economia" tem que ser levado em consideração (EL-KHAFAIFI, 1985): 


\begin{tabular}{|c|c|c|c|}
\hline Termo árabe & Significado & Derivado do vocábulo & E do vocábulo \\
\hline /sarmana/ ${ }^{4}$ & sonambulismo & /sayr/ caminhar & /manān/ sono \\
\hline /barmā'̄ìl & anfíbio & /bar/ terra & /mā’/água \\
\hline /lāmā’̀̄/ & anídrido $^{5}$ & /lā/ partícula de negação & /mâ’/água \\
\hline /lājtimā̄ $\overline{\mathbf{c}}^{-} /$ & antissocial & /lā/ partícula de negação & /ijtima $\bar{a}^{c} \bar{l} /$ social \\
\hline /lākhlāqīi/ & amoral & /lāal partícula de negação & /akhlāqī/ moral \\
\hline
\end{tabular}

Como visto acima, o método de naht pode ser muito produtivo na criação de termos, especialmente daqueles cuja origem são conceitos que foram derivados de vocábulos formados por prefixos e sufixos gregos e latinos.

Assim, chega-se à conclusão que /ichtiqāq/, / ta $^{c}$ rīb/,/majāz/ e /naht/ são os processos utilizados em árabe para a criação de neologismos. A princípio restritos aos tradutores, cada uma dessas ferramentas vem sendo incorporadas por filósofos, terminógrafos e, recentemente, pelas academias de língua em sua tarefa de estandardização do vocabulário em árabe.

\section{Considerações finais}

Está historicamente comprovado que a influência que a língua árabe exerceu sobre os povos conquistados não se limitou ao léxico. Países como o moderno Paquistão, Irã (antiga Pérsia) e Afeganistão também adotaram a escrita árabe para representar os caracteres de suas línguas vernaculares. De uma maneira semelhante, vários povos contribuíram para o enriquecimento da língua árabe. Muitas palavras estrangeiras passaram a fazer parte do léxico árabe não somente durante o período das grandes traduções, mas também depois disso, durante a Renascença Árabe, e em nossos dias, quando os países árabes têm buscado seguir o avanço tecnológico ocidental.

4 Esse termo ilustra bem o princípio de economia. A mesma ideia poderia ser expressa em árabe por uma de duas frases: a. /sayr al-nawm/ (lit. "a perambulação do sono") b. /al-sayr khilāl al-nawm/ (lit. "a perambulação durante o sono").

5 Termo do domínio da química: "Substância derivada de um ácido pela eliminação de uma ou mais moléculas de água” (AURÉLIO, 1999). 
Obviamente, o contato dos árabes com as ciências e as modernas tecnologias ocasionou a inserção de diversos termos no banco de palavras da língua. Os árabes, como todos os povos da Terra, quando confrontados com o surgimento de novas ideias, tiveram que adaptar sua língua para responder ao novo conhecimento. A língua ajustou-se às mudanças usando os recursos disponíveis em sua própria natureza, incluindo o processo de derivação, mas não se limitando a ele. A composição lexical, a arabização (transliteração) de conceitos, a ampliação semântica e os decalques e deslizes linguísticos foram muito usados no processo de fazer a língua árabe mais apropriada para a discussão das ciências até então inexistentes entre eles.

\section{Referências bibliográficas}

ADAMSON, P. (Org). The Cambridge companion to Arabic Philosophy. Cambridge: Cambridge University Press, 2005.

AL-QAHTANI, S. Arabization in written discourse in Saudi Arabia. Muncie/ID, 2000. 247 p. Dissertação (Graduate School) - Ball State University.

AL-QINAI, J. Morphophonemics of loan - Words in translation. In: Majalla Al-lisān al-carabi, 50. pp. 03-34. Rabat: Departamento de Coordenação Permanente, 2001.

ARYAN, R. Arabic roots. Dominguez Hills, CA. 2001. 35 p. Dissertação (Teaching English as a Second Language) - California State University Dominguez Hills.

AT-TARZI, I. The Cairo Language Academy in its 50th anniversary. Cairo: Cairo Language Academy Press, 1999.

BALĀSI, M. Annaḥt fi allogia alcarabiya [A composição lexical na língua árabe]. In: Majalla Al-lisān al-carabi, 47 (1). pp. 275-286. Rabat: Departamento de Coordenação Permanente, 1999.

CHEJNE, A. The Arabic Language. Minnesota: University of Minnesota Press, 1969.

DEMAI, F. M. Um dicionário terminológico da área de ortopedia técnica: descriçấa e análise. São Paulo, 2006. 390 p. Dissertação (Semiótica e Linguística Geral) - Faculdade de Filosofia, Letras e Ciências Humanas, Universidade de São Paulo.

EL-KHAFAIFI, H. M. The role of the Cairo academy in coining a rabic scientific terminolog:: an historical and linguistic evaluation. Utah, 1985, 215 p. Tese de doutoramento (Middle East Studies) - University of Utah Graduate School. 
EL-MOULOUDI, A. Arabic language planning: The case of lexical modernization. Washington, D.C., 1986. 321 p. Tese de doutoramento (Linguística) - Graduate School, Georgetown University.

ESPOSITO, J. The Oxford history of Islam. New York: Oxford University Press, 1999.

FERREIRA, A. B. H. Dicionário Aurélio eletrônico - século XXI. Versão 3.0. São Paulo: Lexikon Informática, 1999.

KENNEDY-DAY, K. Books of definition in Islamic philosophy: The limits of words. London: Routledge, 2003.

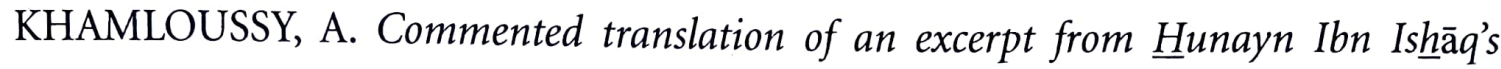
epistle to his patron 'ali Ibn Yahyā on the translations of Galen. Ottawa, 1994. 111 p. Dissertação (School of Translation and Interpretation) - University of Ottawa.

LONGYEAR, C. Linguistics. In: MICROSOFT CORPORATION, Microsoft ${ }^{\circledR}$ Encarta $^{\circledR}$ Encyclopedia. Version 9.0.0.0702. Redmond, WA: Microsoft, 2000.

MATTHEWS, C. M. Words. London: Lutterworth Press, 1979.

TARAZĪ, F. Al-ichtiqāq. Beirut: Librairie du Liban Publishers, 2005.

VERSTEEGH, K. Landmarks in linguistic thought III: The arabic linguistic tradition. London: Routledge, 1997.

WEHR, H. Dictionary of Modern Written Arabic. Ithaca, NY: Spoken Language Services, 1979.

Sistema de transliteração adotado neste artigo

\begin{tabular}{|c|c|c|}
\hline $\begin{array}{l}\text { Grafema } \\
\text { Árabe }\end{array}$ & $\begin{array}{l}\text { Correspondente } \\
\text { na transliteração }\end{array}$ & $\begin{array}{c}\text { Guia de equivalência fonética } \\
\text { no português do Brasil }\end{array}$ \\
\hline 1 & $\overline{\mathrm{a}}$ & "a" longo (ah) \\
\hline$\varphi$ & $\mathrm{b}$ & "b" como em bota \\
\hline 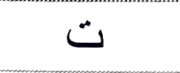 & $\mathrm{t}$ & " $t$ " como em tapete \\
\hline$\dot{H}$ & $\underline{\text { th }}$ & "th" como no inglês "thin" \\
\hline ج & $\mathrm{j}$ & “j” como em jogo \\
\hline$\tau$ & h & "h" do inglês sem aspiração \\
\hline$\dot{\tau}$ & $\underline{\mathrm{kh}}$ & "rr" como em carro no dialeto carioca \\
\hline د & $\mathrm{d}$ & "d" como em delta \\
\hline
\end{tabular}


(continuação)

\begin{tabular}{|c|c|c|}
\hline $\begin{array}{c}\text { Grafema } \\
\text { Árabe }\end{array}$ & $\begin{array}{l}\text { Correspondente } \\
\text { na transliteração }\end{array}$ & $\begin{array}{c}\text { Guia de equivalência fonética } \\
\text { no português do Brasil }\end{array}$ \\
\hline$j$ & $\underline{\mathrm{d}}$ & "th" como no inglês "this" \\
\hline$\jmath$ & $\mathrm{r}$ & "r" como em careta \\
\hline j & $\mathrm{Z}$ & "z" como em zabumba \\
\hline 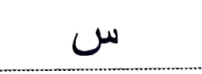 & $s$ & "s" como em sapo \\
\hline ش & $\underline{\mathrm{ch}}$ & "ch" como em chave \\
\hline ص ص ص ص ص & $\underline{\mathbf{s}}$ & som similar ao "s" em sapo, porém enfático \\
\hline ض & de & som de "d" em delta, porém enfático \\
\hline b & $\underline{\mathrm{t}}$ & som de "t" em tapete, porém enfático \\
\hline ظ & $\mathrm{Z}$ & som similar ao " $z$ " em zero, porém enfático \\
\hline$\varepsilon$ & c & $\begin{array}{l}\text { som gutural sem equivalência em } \\
\text { português }\end{array}$ \\
\hline$\dot{\varepsilon}$ & $\dot{\mathrm{g}}$ & "r" como no francês parisiense "rat" \\
\hline ف & $\mathrm{f}$ & "f" como em faca \\
\hline ق & $\mathrm{q}$ & semelhante ao "k" porém mais gutural \\
\hline 5 & $\mathrm{k}$ & "c" como em copo \\
\hline J & 1 & "l" como em laranja \\
\hline 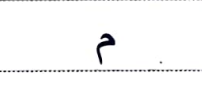 & $\mathrm{m}$ & "m" como em marca \\
\hline$\dot{ن}$ & $\mathrm{n}$ & "n" como em navio \\
\hline$\triangle$ & $\mathrm{h}$ & "h" como no inglês "hospital" \\
\hline 9 & $\mathrm{w} / \overline{\mathrm{u}}$ & “u” longo (uh) \\
\hline ي & $y / \overline{1}$ & "i" longo (ih) \\
\hline 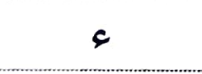 & , & parada glotal \\
\hline
\end{tabular}

